\title{
Platelet-Activating Factor Induces Dual-Specificity Phosphatase 1 and 5 Gene Expression
}

\author{
Fanny Lapointe, Michael Stiffel, Jean-Philippe Auger, Marek Rola-Pleszczynski, \\ Jana Stankova \\ Division of Immunology and Allergy, Department of Pediatrics, Faculty of Medicine and Health Sciences, \\ Université de Sherbrooke, Sherbrooke, Canada \\ Email: Jana.Stankova@USherbrooke.ca
}

Received 15 August 2015; accepted 18 September 2015; published 21 September 2015

Copyright (C) 2015 by authors and Scientific Research Publishing Inc.

This work is licensed under the Creative Commons Attribution International License (CC BY). http://creativecommons.org/licenses/by/4.0/

C. (i) Open Access

\begin{abstract}
Platelet-activating factor (PAF) is a potent inflammatory phospholipid mediator that is known to play a role in early-phase responses in asthma and other diseases. Through its high affinity receptor, PAFR, PAF is known to activate multiple signalling pathways contributing to its proinflammatory effects. Of these pathways, the mitogen-activated protein kinase (MAPK) cascade is initiated upon PAF stimulation, leading to the activation of the conventional MAPKs ERK1/2, p38 and JNK. Since dual-specificity phosphatases (DUSP) downregulated MAPK activity, we postulated that PAF could also enhance DUSP expression and thus induced an autoregulatory loop. In this report, we studied the effect of PAF on DUSP mRNA expression in human monocytes. Our results demonstrate that PAF induces DUSP1 and DUSP5 gene expression in a time- and concentration-dependent manner, with maximal effects at PAF $100 \mathrm{nM}$ and at 20 - 30 min of stimulation. In contrast, DUSP2 and DUSP6 gene expression was not enhanced by PAF. Moreover, leukotriene D4, another lipid mediator of inflammation, was unable to modulate DUSP expression. PAF-induced DUSP expression was prevented by the PAFR antagonist WEB2170 and by pretreatment with the transcriptional inhibitor Actinomycin D. Moreover, enhanced DUSP5, but not DUSP1 expression was prevented by pretreatment with the ERK inhibitor PD98059 or the PI3K inhibitor Wortmannin. Taken together, our results indicate that PAF selectively enhances DUSP1 and DUSP5 gene expressions through PAFR activation, and suggest that PAF may have an active role in the resolution of inflammation by its ability to upregulate the two DUSPs and thus provide a negative auto-regulatory signalling mechanism.
\end{abstract}

\section{Keywords}

Inflammation, Asthma, PAF, Dual-Specificity Phosphatase, MAPK, PI3K

How to cite this paper: Lapointe, F., Stiffel, M., Auger, J.-P., Rola-Pleszczynski, M. and Stankova, J. (2015) Platelet-Activating Factor Induces Dual-Specificity Phosphatase 1 and 5 Gene Expression. Pharmacology \& Pharmacy, 6, 442-450. 


\section{Introduction}

Platelet activating factor (PAF) ${ }^{1}$ is a potent phospholipid mediator that has a role in an array of inflammatory diseases [1]. It is secreted by a wide variety of cells including leukocytes and endothelial cells [2].

PAF-induced effects are mediated through activation of its high-affinity, widely expressed receptor, PAFR, a G-protein-coupled receptor. PAF is known to induce the activation of multiple signalling pathways leading to expression of a number of cytokines and chemokines, thus contributing to the proinflammatory effects of the lipid. One of these, the mitogen-activated protein kinase (MAPK) cascade is initiated early upon PAF stimulation [3]-[5] leading to the activation of the conventional MAPKs ERK1/2, p38 and JNK [6]-[8]. ERK1 and ERK2 are mainly implicated in the proliferation and differentiation processes, whereas p38 is associated with pro-inflammatory cytokine production and JNK, with regulation of extracellular matrix [9].

In contrast, dual-specificity phosphatases (DUSPs) are involved in preventing MAPK signalling. In mammalian cells, DUSPs are represented by 10 catalytically active phosphatases divided in three sub-families. Of these, the nuclear mitogen kinase phosphatase 1 (MKP-1) (encoded by the DUSP1 gene), a member of the Stress-Inducible sub-family [10], is the prototypical member of the DUSP family that dephosphorylates MAPKs (JNK, p38, >ERK1/2) in a cell-type dependent manner. DUSP1 has been linked to innate immunity and inflammatory diseases, as DUSP1 ${ }^{-/}$mice show enhanced inflammatory cytokine levels [11] [12]. Moreover, subjects with severe asthma demonstrate lower DUSP1 expression compared to control subjects [13]. On the other hand, VH3 (encoded by DUSP5 gene), may also be involved in resolution of inflammation through its ability to inhibit and anchor nuclear ERK1/2 [14]. Furthermore, DUSP5 was shown to be upregulated in cases of sustained inflammation [15] and was presented as a key anti-apoptotic molecule in activated eosinophils [16].

We postulated that PAF could enhance DUSP expression and thus induce a negative, autoregulatory loop. Here, we demonstrate that PAF induces DUSP1 and DUSP5 mRNA upregulation in a time- and concentrationdependent manner in human monocytes through a mechanism involving receptor-mediated signalling and gene transcription.

\section{Materials and Methods}

\subsection{Cells}

Human monocytes were isolated from peripheral blood mononuclear leukocytes (PBMLs) obtained from healthy donors after informed consent, in accordance with an internal review board-approved protocol, according to the technique described by Böyum [17]. PBMLs were firstly enriched by sedimentation using Dextran T500 (Pharmacosmos, Holbaek, Denmark) followed by a density gradient centrifugation on Ficoll-Paque ${ }^{\mathrm{TM}}$ Plus (GE Hearthcare, Mississauga, ON, Canada). Mononuclear cells were collected at the interface of the Ficoll and monocytes were then purified by petri dish adherence using dishes previously coated with defibrinized autologous serum. Monocytes were resuspended in RPMI 1640 medium (Gibco ${ }^{\circledR}$, Burlington, ON, Canada) supplemented with $10 \%$ fetal bovine serum (FBS) (PAA, Piscataway, NJ, USA), $100 \mu \mathrm{g} / \mathrm{mL}$ penicillin G (PPC inc., Richmond Hill, ON, Canada) and $100 \mu \mathrm{g} / \mathrm{mL}$ streptomycin (Sigma-Aldrich, St. Louis, MO, USA). Cells were rested overnight under normal conditions $-37^{\circ} \mathrm{C}+5 \% \mathrm{CO}_{2}$-in round bottom $15 \mathrm{~mL}$ polypropylene tubes at $1 \times 10^{6} \mathrm{mo}-$ nocytes/mL.

Before experiments, cells were centrifuged and resuspended at $2 \times 10^{6}$ monocytes $/ \mathrm{mL}$ and starved for 3 hours in RPMI 1640 medium without serum. Cells were then pre-treated, as described, with WEB2170, Actinomycin D, Wortmannin or MAPK inhibitors for 30 minutes, and stimulated for the appropriated time with PAF or $\mathrm{LTD}_{4}$ at indicated concentrations.

\subsection{Reagents}

Reagents used in this paper were purchased from the following sources: PAF C-16, LTD 4 , SB203580, PD98059, SP600125 and Wortmannin were purchased from Cayman Chemical (Ann Arbor, MI, USA). WEB2170 was from Boehringer Ingelheim (Burlington, ON, Canada). Actinomycin D was purchased from Biovision, Inc. (Milpitas, CA, USA).

${ }^{1}$ PAF, platelet-activating factor; PAFR, PAF receptor; DUSP, dual-specificity phosphatase; MAPK, mitogen-activated protein kinase; PI3K, phosphatidyl-inositol-3-kinase; ERK, extracellular receptor kinase; JNK, jun N-terminal kinase. 


\subsection{RNA Isolation and RT-PCR}

Total RNA was purified using Trizol ${ }^{\circledR}$ (Life Technologies ${ }^{\mathrm{TM}}$, Burlington, ON, Canada) according to the manufacturer's instructions using the classical phenol/chloroform technique. To exclude genomic DNA contamination, $1.5 \mu \mathrm{g}$ of RNA was digested with RNasin ${ }^{\circledR}$ (Promega, Madison, WI, USA) and DNase 1 (Thermo Scientific, Ottawa, ON, Canada). The reaction was stopped with $25 \mu \mathrm{M}$ EDTA. First-strand cDNA synthesis was performed on this pre-treated RNA using oligo(dT) ${ }_{18}$ primer (Thermo Scientific) and M-MLV reverse transcriptase (Promega) in a final volume of $22 \mu \mathrm{L}$.

\subsection{Real-Time Quantitative PCR}

GAPDH, DUSP1, DUSP2, DUSP5 and DUSP6 expression was measured using real-time quantitative PCR performed on a Rotor Gene 3000 from Corbett Research (San Francisco, CA, USA). According to the optimized protocol, $35 \mathrm{ng}$ of reverse transcription product was mixed with $0.5 \mu \mathrm{M}$ forward and reverse primers (IDT ${ }^{\circledR}$, Coralville, Iowa, USA), 1.25 units of TAQ DNA polymerase (Feldan, Quebec, QC, Canada), 0.2 mMdNTPs (Feldan, Quebec, QC, Canada), 1 mM MgCL 2 (Thermo Scientific, Lafayette, CO, USA), and 1:32,500 final dilution of SYBR Green (Molecular Probes ${ }^{\circledR}$, Burlington, ON, Canada) in supplied TAQ DNA polymerase buffer, for a final volume of $52 \mu \mathrm{L}$.

The primer sequences were obtained from IDT ${ }^{\circledR}$ : GAPDH forward, 5'-TCA ACG GAT TTG GTC GTC TTG-3'; GAPDH reverse, 5'-GAT GGG ATT TCC ATT GAT GAC A-3'; DUSP1 forward, 5'-CGA GGC CAT TGA CTT CAT AG-3'; DUSP1 reverse, 5'-TGA AGC TGA AGT TGG GAG AG-3'; DUSP2 forward, 5'-GAT CTT GCC CTA CCT GTT CC-3'; DUSP2 reverse, 5'-CCC AGT CAA TGA AGC CTA TG-3'; DUSP5 forward, 5'-CGG AAT ATC CTG AGT GTT GC-3'; DUSP5 reverse, 5'-AAG GGA AGG ATT TCA ACT GG-3'; DUSP6 forward, 5'-TCA AGA AGC TCA AGG ACG AG-3' and DUSP6 reverse, 5'-GCT GAC CCA TGA AGT TGA AG-3'. PCR was started with a 5 minute hold step at $95^{\circ} \mathrm{C}$, followed by 40 repeats of the cycling step: 30 seconds at $95^{\circ} \mathrm{C}, 30$ seconds at $58^{\circ} \mathrm{C}$, and 30 seconds at $72^{\circ} \mathrm{C}$ (acquiring on Fam/syb) and ended by a final extension at $72^{\circ} \mathrm{C}$ for 6 minutes, then a melt step rising from $72^{\circ} \mathrm{C}$ to $95^{\circ} \mathrm{C}$. Data analysis was performed according to the $2^{-\Delta \Delta \mathrm{CT}}$ method as previously described [18].

\subsection{Statistical Analyses}

Statistical analyses were performed using Prism 6.0 software (GraphPad). Data were analyzed using one way ANOVA or one-tailed, paired Student's $t$ test as appropriate. A $p$ value of $<0.05$ was considered statistically significant.

\section{Results}

\subsection{Human Monocytes Express Mainly DUSP1 and DUSP5}

Using human monocytes, we first studied the mRNA expression levels of four common DUSPs (DUSP1, DUSP2, DUSP5, DUSP6). Unstimulated human monocytes mainly expressed DUSP1 and DUSP5 as compared to DUSP2 and DUSP6 (Figure 1). Both DUSP1 and DUSP5 have been implicated in inflammation [12] [15] and DUSP1 expression was shown to be upregulated in airway smooth muscle cells and in monocytes/macrophages in response to inflammatory stimuli [19] [20]. We thus proceeded to study the potential effect of PAF on DUSP1 and DUSP5 gene expression.

\subsection{PAF Induces DUSP1 and DUSP5 Expression}

When human monocytes were exposed to PAF $10 \mathrm{nM}$ for periods of time between 10 to 120 minutes, both DUSP1 and DUSP5 gene expression was significantly enhanced, but with an earlier and greater effect on DUSP1 expression (Figure 2(a), Figure 3(a)). Maximal expression of DUSP1 was observed between 20 to 30 minutes, whereas that of DUSP5, between 30 to 45 minutes, with a slow recovery to the basal expression state from 30 to 120 minutes. However, both phosphatases showed the same expression pattern when exposed to graded concentrations of PAF (0.001 nM to $100 \mathrm{nM})$ for 30 minutes with a maximal response at PAF $100 \mathrm{nM}$ (Figure 2(b), Figure 3(b)).

Moreover, when human monocytes were pre-incubated for 30 minutes with WEB2170 (10 $\mu \mathrm{M})$, a PAFR 


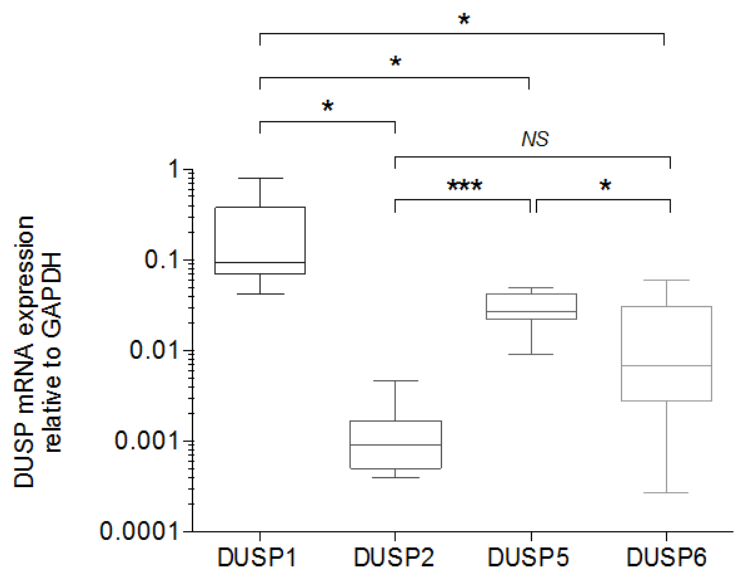

Figure 1. Basal expression of DUSP1, DUSP2, DUSP5 and DUSP6 mRNA relative to GAPDH in human monocytes. Cells were starved for 3 hours in RPMI 1640 medium without serum before lysis. Relative mRNA expression is presented as fold over GAPDH expression $\left(2^{-\Delta \mathrm{CT}}\right)$ using quantitative real-time PCR $\left({ }^{*} p<0.05,{ }^{* * *} p<0.001\right.$ using Student's $t$ test; $\mathrm{n}=11$ ).

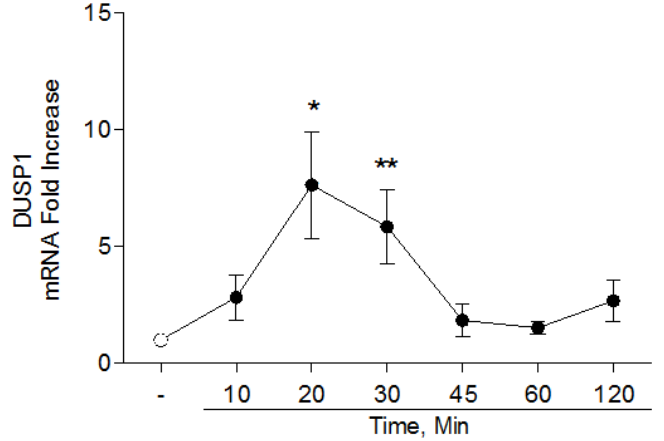

(a)

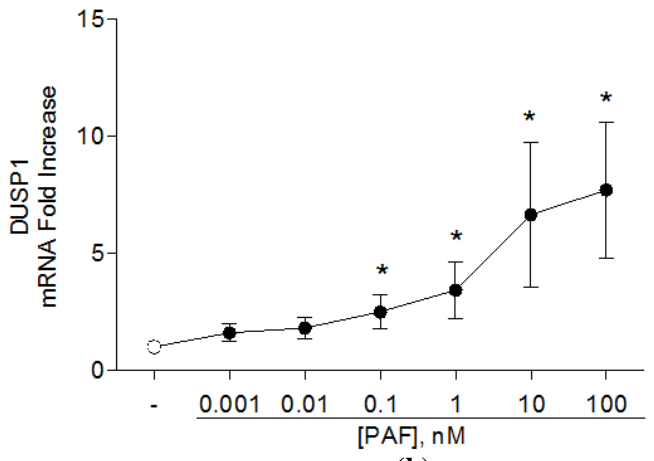

(b)

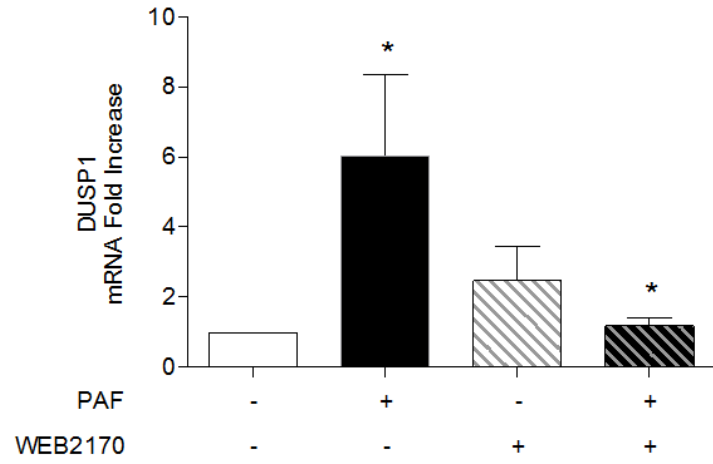

(c)

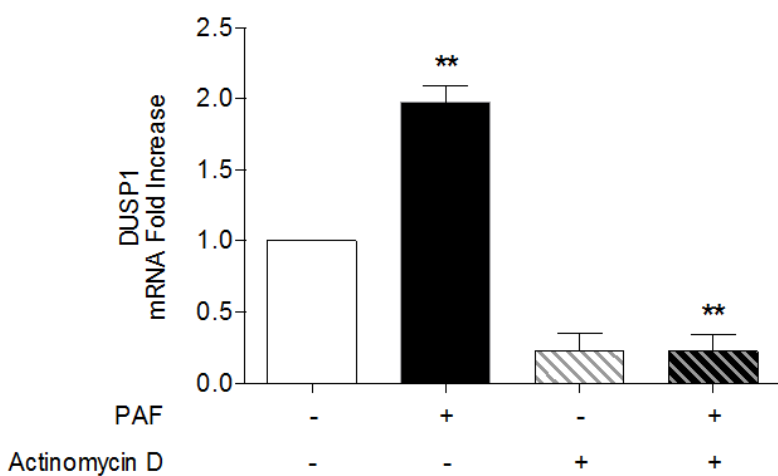

(d)

Figure 2. Modulation of DUSP1 mRNA expression by PAF in human monocytes. Cells were starved 3 hours in RPMI 1640 medium without serum before stimulation with PAF. (a) Monocytes were stimulated with PAF $10 \mathrm{nM}$ for the indicated time (minutes) ( $\mathrm{n}=4$ - 8). (b) Monocytes were stimulated with graded concentrations of PAF (nM) for 30 minutes $(\mathrm{n}=10)$. Monocytes were pre-incubated for 30 minutes with WEB2170 $(10 \mu \mathrm{M})(\mathrm{n}=6)(\mathrm{c})$ or Actinomycin D $(10 \mu \mathrm{M})(\mathrm{n}=4)(\mathrm{d})$ before a 30 minute stimulation with PAF $10 \mathrm{nM}$. mRNA expression was quantified using quantitative real-time PCR. Data are expressed as fold increase relative to non-stimulated condition (-) (a)-(d) or to PAF (10 nM) (c) (d) $\left({ }^{*} p<0.05,{ }^{* *} p<\right.$ 0.01 using Student's $t$ test). 


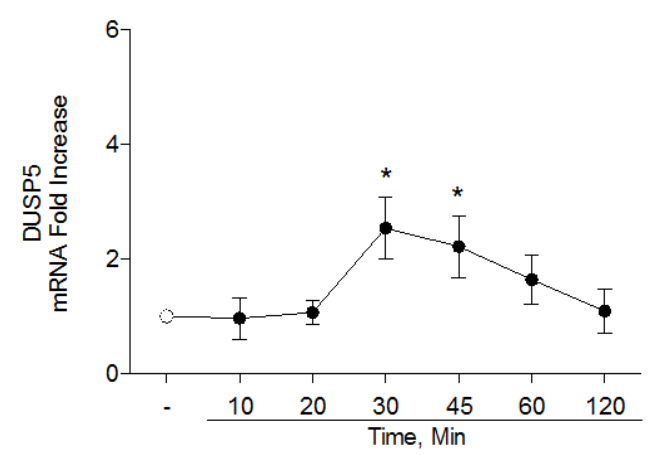

(a)

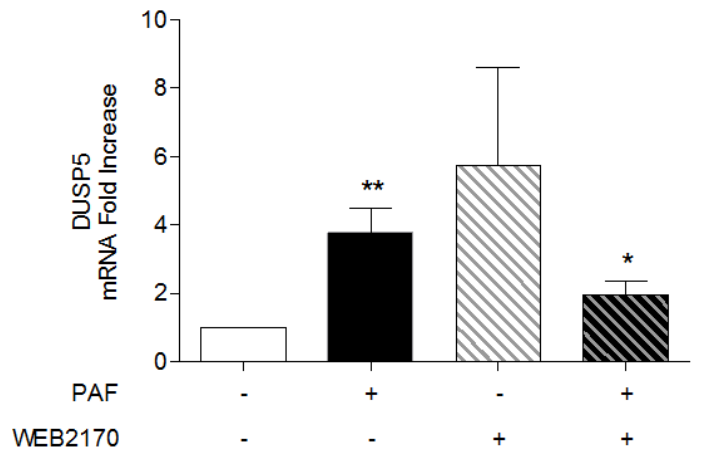

(c)

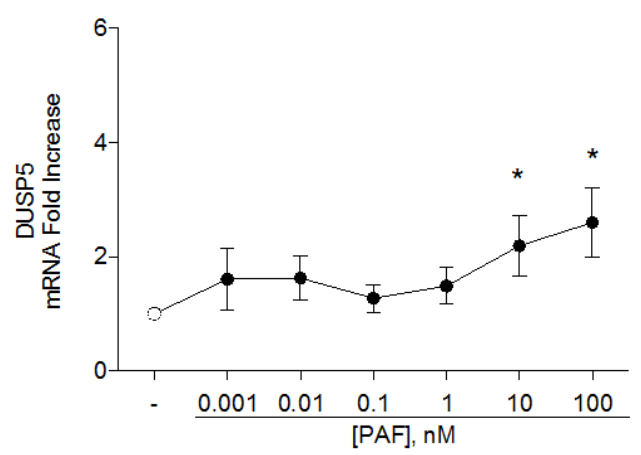

(b)

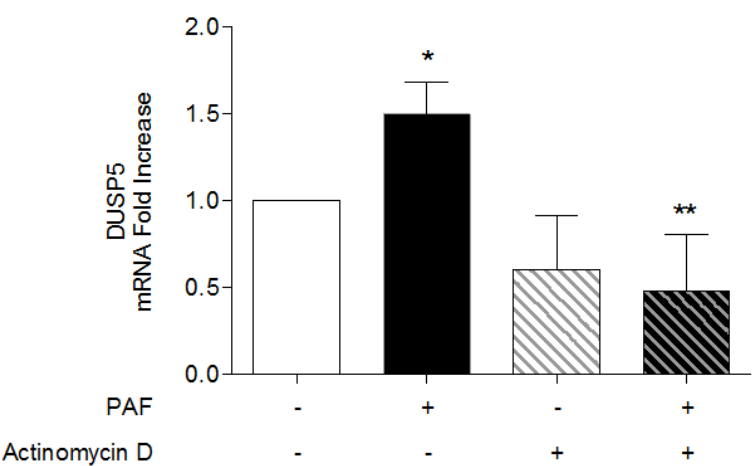

(d)

Figure 3. Modulation of DUSP5 mRNA expression by PAF in human monocytes. Cells were starved 3 hours in RPMI 1640 medium without serum before stimulation with PAF. (a) Monocytes were stimulated with PAF $10 \mathrm{nM}$ for the indicated time (minutes) $(n=4-8)$. (b) Monocytes were stimulated with graded concentrations of PAF (nM) for 30 minutes $(n=10)$. Monocytes were pre-incubated for 30 minutes with WEB2170 $(10 \mu M)(n=6)(c)$ or Actinomycin D $(10 \mu \mathrm{M})(\mathrm{n}=4)(\mathrm{d})$ before a 30 minute stimulation with PAF $10 \mathrm{nM}$. mRNA expression was quantified using quantitative real-time PCR. Data are expressed as fold increase relative to non-stimulated condition (-) (a)-(d) or to PAF $(10 \mathrm{nM})(\mathrm{c})(\mathrm{d})\left(^{*} p<0.05,{ }^{* *} p<0.01\right.$ using Student's $t$ test $)$.

antagonist, the PAF-induced increase in DUSP1 and DUSP5 mRNA expression was abolished (Figure 2(c), Figure 3(c)). Pretreatment with the transcriptional inhibitor Actinomycin D $(10 \mu \mathrm{M})$ also blocked DUSP mRNA upregulation upon PAF stimulation (Figure 2(d), Figure 3(d)). Thus, our results demonstrate that PAF, acting through its high affinity receptor PAFR, induced DUSP1 and DUSP5 mRNA expression in a time- and concentration-dependent manner, and through a transcription-dependent process. Moreover, the PAF effect was selective, as DUSP2 and DUSP6 expression was not affected upon PAF stimulation (data not shown).

\subsection{TTD $_{4}$ Does Not Induce DUSP Expression}

We next investigated whether another inflammatory lipid mediator could also modulate DUSP expression. Since cysteinyl-leukotrienes are also involved in asthmatic symptoms [21], we exposed human monocytes to LTD $_{4}$ (100 nM) from 30 minutes to 24 hours, but could observe no significant DUSP mRNA modulation (data not shown).

\subsection{PAF-Induced DUSP5, But Not DUSP1, Expression Is Dependent on PI3K and MAPK Activation}

We next investigated the PAFR signalling pathways leading to DUSP1 and DUSP5 mRNA upregulation. We first determined whether DUSP1 and DUSP5 mRNA upregulation was dependent on the activation of the phosphatidylinositol 3-kinase (PI3K). To this end, Wortmannin $(0.1 \mu \mathrm{M})$, a PI3K inhibitor, was added 30 minutes before stimulation with PAF (10 nM). As shown in Figure 4, inhibition of PI3K activation abolished PAF-in-duced 


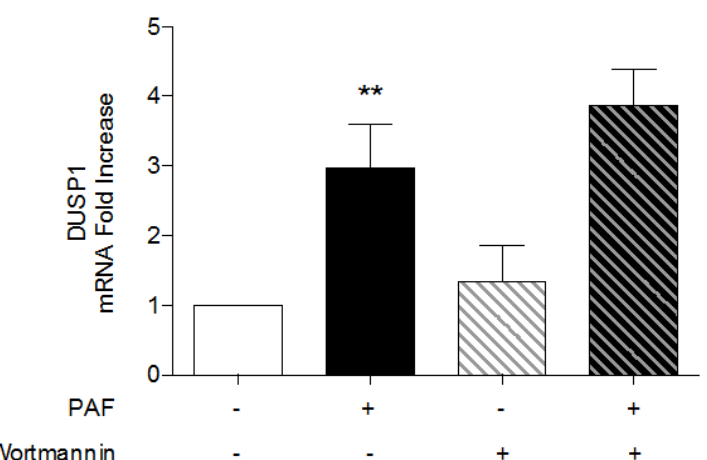

(a)

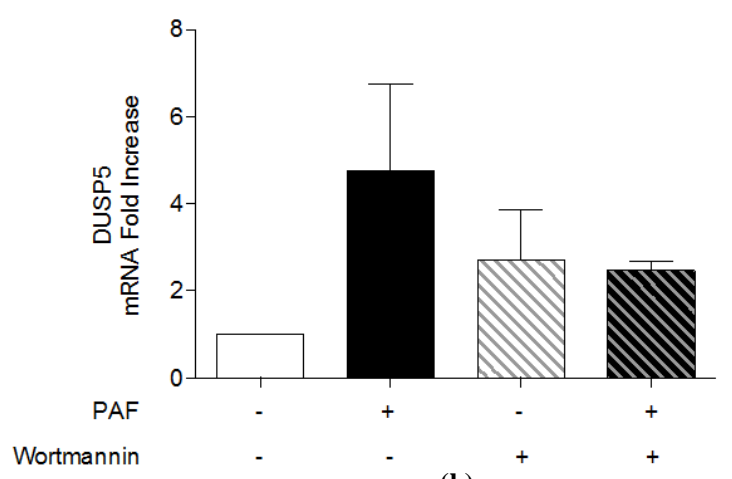

(b)

Figure 4. PI3K involvement in PAF-stimulated DUSP1 and DUSP5 mRNA expression in human monocytes. Cells were starved 3 hours in RPMI 1640 medium without serum before stimulation with PAF $10 \mathrm{nM}$ for 30 minutes, following a 30 minute pre-incubation with medium or Wortmannin $(0.1 \mu \mathrm{M})$. DUSP1 $(n=3-5)(a)$ and DUSP5 $(n=2)(b)$ mRNA was quantified using quantitative real-time PCR. Data are expressed as fold increase relative to non-stimulated condition (-) or to PAF $(10 \mathrm{nM})(* * p<0.01$ using Student's $t$ test $)$.

DUSP5, but not DUSP1 mRNA upregulation. Therefore, DUSP1 and DUSP5 expression appears not to be upregulated via the same pathway.

Subsequently, the potential role for the MAPK signalling cascade was investigated. As shown in Figure 5(a)-(c), the use of PD58059 $(10 \mu \mathrm{M})$, a MEK1/2 inhibitor, or the use of SP600125 (5 $\mu \mathrm{M})$ or SB203580 (10 $\mu \mathrm{M})$, inhibitors of the JNK and p38 pathways, respectively, failed to affect DUSP1 mRNA expression upon PAF $(10 \mathrm{nM})$ stimulation. Similarly, combinations of MAPK inhibitors had no effect on DUSP1 mRNA expression (data not shown).

In contrast, our results demonstrate that the MEK/ERK and JNK pathways may be involved in the modulation of DUSP5 mRNA expression as the use of either PD58059 $(10 \mu \mathrm{M})$ or SP600125 $(5 \mu \mathrm{M})$ inhibited PAF-induced DUSP5 mRNA expression (Figure 5(d)-(e)). Inhibition of p38, however, was ineffective (Figure 5(f)). Combinations of MAPK inhibitors revealed no further effects on DUSP5 mRNA expression (data not shown).

\section{Discussion}

PAF, a potent inflammatory lipid, is known to be implicated in a wide variety of inflammatory diseases. Through its high affinity receptor PAFR, PAF can induce multiple signalling pathways leading to expression of a number of cytokines and chemokines, thus contributing to the proinflammatory effects of the lipid. Of these pathways, the mitogen-activated protein kinase (MAPK) cascade initiated upon PAF stimulation [3]-[5] activates the conventional MAPKs ERK1/2, p38 and JNK [6]-[8] that can subsequently be inactivated with selective DUSPs.

Here, we show that human monocytes mainly express DUSP1 and that PAF enhances DUSP1 and DUSP5 gene expression in a time-, concentration- and transcription-dependent manner. Our results show that PAF (10 $\mathrm{nM}$ ) induces maximal DUSP1 mRNA expression as early as 20 to 30 minutes, whereas maximal DUSP5 expression is observed at 30 to 45 minutes. Indeed, DUSP1 has been characterized as an early response gene [22], whereas DUSP5 was described as a late gene [23]. However, despite differences in time-dependent mRNA modulation, the expression of both phosphatases was similar in a concentration-response to PAF ( $0.001 \mathrm{nM}$ to $100 \mathrm{nM}$ ). We also demonstrated that both DUSP1 and DUSP5 mRNA upregulation was dependent on PAFR activation and on gene transcription.

Human monocytes show a higher expression level of DUSP1 than DUSP2, DUSP5 or DUSP6. This could explain why DUSP1 gene expression is more strongly upregulated when cells are stimulated with PAF. DUSP1 may thus be a leading candidate for resolution of PAF-induced inflammation as it is rapidly and significantly induced by PAF.

In concordance with previous data linking DUSP1 and DUSP5 with inflammatory diseases, PAF-induced DUSP1 and DUSP5 gene upregulation may be relevant to the mechanisms of asthma. Notably, DUSP1 was first linked to innate immunity in DUSP ${ }^{-/}$mice in which elevated cytokine levels were quantified [12] [24]. It was also shown that Dexamethasone, an anti-inflammatory glucocorticoid, enhances DUSP1 expression in order to 


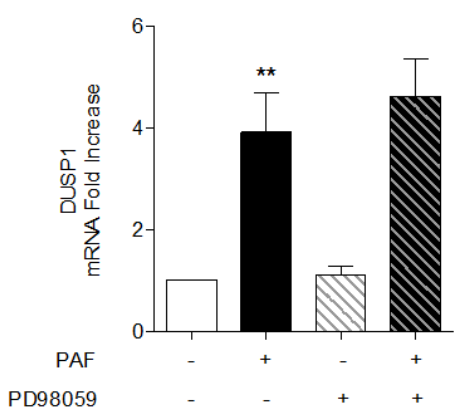

(a)

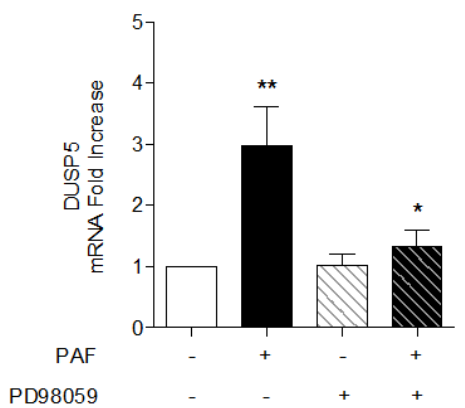

(d)

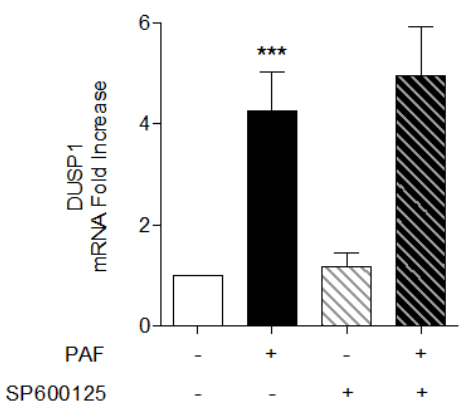

(b)

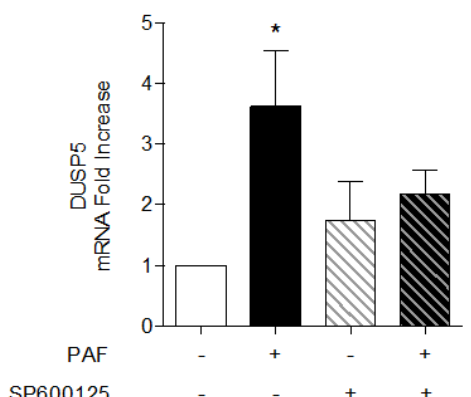

(e)

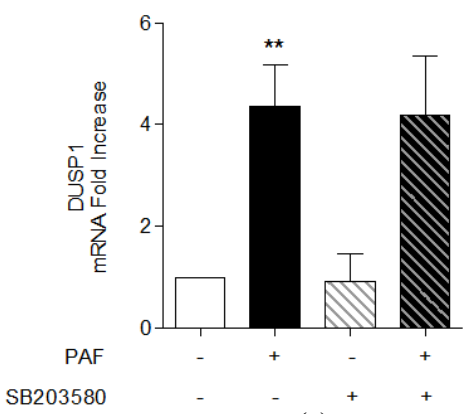

(c)

Figure 5. MAPK involvement in PAF-stimulated DUSP1 and DUSP5 mRNA expression in human monocytes. Cells were starved 3 hours in RPMI 1640 medium without serum before stimulation with PAF. Monocytes were stimulated with PAF $10 \mathrm{nM}$ for 30 minutes following a 30 minute pre-incubation with PD98059 $(10 \mu \mathrm{M})(\mathrm{n}=10)(\mathrm{a})(\mathrm{d})$, SP600125 $(5 \mu \mathrm{M})(\mathrm{n}=11)$ (b) (e), or SB203580 (10 $\mu \mathrm{M})(\mathrm{n}=9)(\mathrm{C}, \mathrm{F})$. DUSP1 (a)-(c) and DUSP5 (d)-(f) mRNA was quantified using quantitative real-time PCR. Data are expressed as fold increase relative to non-stimulated condition (-) or to PAF $(10 \mathrm{nM})\left({ }^{*} p<0.05,{ }^{* *} p<0.01,{ }^{* * *} p<0.001\right.$ using Student's $t$ test $)$.

transiently repress inflammatory genes implicated in human asthma [25]. The phosphatase was further characterized as an immune modulator by its capacity to mediate the anti-inflammatory effect of glucocorticoids in airways smooth muscle cells by inhibition of TNF $\alpha$-induced pro-inflammatory cytokines [19] [26]. Moreover, a DUSP1 polymorphism (rs881152) was linked to a better response of asthmatic patients to inhaled corticosteroids [27]. In contrast, subjects with severe asthma were found to express significantly less DUSP1, resulting in an increased p38 activation in alveolar macrophages, and enhanced asthmatic symptoms [13]. On the other hand, the less common DUSP5 may play a different role in inflammatory pathologies such as human asthma. DUSP5 may be involved in eosinophil survival, as an anti-apoptotic signalling component [16], and its expression was reported to be elevated in sustained inflammation [15].

PAF-induced expression of DUSP1 and DUSP5 appears to be selective, as DUSP2 and DUSP6 mRNA levels were not modulated upon PAF stimulation. DUSP2 is a member of the Stress-Inducible MAPK phosphatases, along with DUSP1. However, in contrast to DUSP1, DUSP2 ${ }^{-/}$mice were found to have less inflammation in an autoimmune model of rheumatoid arthritis, suggesting that DUSP2 may have a positive activating effect on immune cells and inflammatory responses [28].

As for DUSP6, it is an ERK-specific member of the second MAPK phosphatase sub-family [10] and appears not to be involved in the immune system. The evidence supplied by a DUSP6 ${ }^{-/-}$mouse model indicates that DUSP6 may be implicated in somatic development as dwarfism was found in these mice as well as a premature fusion of the cranial suture and a defect in ear bones [29]. Also, DUSP6 is likely to be implicated in mood and bipolar disorders [11].

\section{Conclusion}

In conclusion, our results indicate that PAF selectively enhances DUSP1 and DUSP5 gene expression through PAFR activation, and suggest that PAF may have an active role in the resolution of inflammation by its ability 
to upregulate these two DUSPs and thus provide a negative auto-regulatory signalling mechanism.

\section{Acknowledgements}

The authors declare that there is no conflict of interest. The authors are grateful to the blood donors for their generosity.

This work was supported by a grant to J.S. and M.R.-P. from the Canadian Institutes of Health Research. J.S. and M.R.-P. are members of the FRQS-funded Centre de recherche du Centre hospitalier universitaire de Sherbrooke. M.R.-P. was the recipient of a Canada Research Chair in Inflammation.

\section{References}

[1] Izumi, T. and Shimizu, T. (1995) Platelet-Activating Factor Receptor: Gene Expression and Signal Transduction. Biochimica et Biophysica Acta, 3, 317-333. http://dx.doi.org/10.1016/0005-2760(95)00171-9

[2] Kasperska-Zajac, A., Brzoza, Z. and Rogala, B. (2008) Platelet Activating Factor as a Mediator and Therapeutic Approach in Bronchial Asthma. Inflammation, 2, 112-120. http://dx.doi.org/10.1007/s10753-007-9056-9

[3] Marques, S.A., Dy, L.C., Southall, M.D., Yi, Q., Smietana, E., Kapur, R., Marques, M., Travers, J.B. and Spandau, D.F. (2002) The Platelet-Activating Factor Receptor Activates the Extracellular Signal-Regulated Kinase Mitogen-Activated Protein Kinase and Induces Proliferation of Epidermal Cells through an Epidermal Growth Factor-Receptor-Dependent Pathway. Journal of Pharmacology and Experimental Therapeutics, 3, 1026-1035. http://dx.doi.org/10.1124/jpet.300.3.1026

[4] Honda, Z., Takano, T., Gotoh, Y., Nishida, E., Ito, K. and Shimizu, T. (1994) Transfected Platelet-Activating Factor Receptor Activates Mitogen-Activated Protein (Map) Kinase and Map Kinase Kinase in Chinese Hamster Ovary Cells. Journal of Biological Chemistry, 3, 2307-2315.

[5] Chen, Z., Rola-Pleszczynski, M. and Stankova, J. (2003) Activation of Erk1/2 by Platelet-Activating Factor Receptor Is Independent of Receptor Internalization and G-Protein Activation. Cell Signal, 9, 843-850. http://dx.doi.org/10.1016/S0898-6568(03)00056-1

[6] Nick, J.A., Avdi, N.J., Young, S.K., Knall, C., Gerwins, P., Johnson, G.L. and Worthen, G.S. (1997) Common and Distinct Intracellular Signaling Pathways in Human Neutrophils Utilized by Platelet Activating Factor and Fmlp. Journal of Clinical Investigation, 5, 975-986. http://dx.doi.org/10.1172/JCI119263

[7] Maruoka, S., Hashimoto, S., Gon, Y., Takeshita, I. and Horie, T. (2000) PAF-Induced Rantes Production by Human Airway Smooth Muscle Cells Requires Both P38 Map Kinase and Erk. American Journal of Respiratory and Critical Care, 161, 922-929. http://dx.doi.org/10.1164/ajrccm.161.3.9906059

[8] Miike, S., Kurasawa, K., Saito, Y. and Iwamoto, I. (2000) Platelet-Activating Factor Activates Mitogen-Activated Protein Kinases through the Activation of Phosphatidylinositol 3-Kinase and Tyrosine Kinase in Human Eosinophils. Journal of Leukocyte Biology, 1, 117-126.

[9] Patterson, H., Nibbs, R., McInnes, I. and Siebert, S. (2014) Protein Kinase Inhibitors in the Treatment of Inflammatory and Autoimmune Diseases. Clinical \& Experimental Immunology, 1, 1-10. http://dx.doi.org/10.1111/cei.12248

[10] Caunt, C.J. and Keyse, S.M. (2013) Dual-Specificity Map Kinase Phosphatases (Mkps): Shaping the Outcome of Map Kinase Signalling. FEBS Journal, 2, 489-504. http://dx.doi.org/10.1111/j.1742-4658.2012.08716.X

[11] Hendriks, W.J., Elson, A., Harroch, S., Pulido, R., Stoker, A. and den Hertog, J. (2013) Protein Tyrosine Phosphatases in Health and Disease. FEBS Journal, 280, 708-730. http://dx.doi.org/10.1111/febs.12000

[12] Wancket, L.M., Frazier, W.J. and Liu, Y. (2012) Mitogen-Activated Protein Kinase Phosphatase (Mkp)-1 in Immunology, Physiology, and Disease. Life Sciences, 90, 237-248. http://dx.doi.org/10.1016/j.lfs.2011.11.017

[13] Bhavsar, P., Hew, M., Khorasani, N., Torrego, A., Barnes, P.J., Adcock, I. and Chung, K.F. (2008) Relative Corticosteroid Insensitivity of Alveolar Macrophages in Severe Asthma Compared with Non-Severe Asthma. Thorax, 63, 784-790. http://dx.doi.org/10.1136/thx.2007.090027

[14] Mandl, M., Slack, D.N. and Keyse, S.M. (2005) Specific Inactivation and Nuclear Anchoring of Extracellular Signal-Regulated Kinase 2 by the Inducible Dual-Specificity Protein Phosphatase DUSP5. Molecular and Cellular Biology, 25, 1830-1845. http://dx.doi.org/10.1128/MCB.25.5.1830-1845.2005

[15] Halle, M., Gabrielsen, A., Paulsson-Berne, G., Gahm, C., Agardh, H.E., Farnebo, F. and Tornvall, P. (2010) Sustained Inflammation Due to Nuclear Factor-Kappa B Activation in Irradiated Human Arteries. Journal of the American College of Cardiology, 55, 1227-1236. http://dx.doi.org/10.1016/j.jacc.2009.10.047

[16] Temple, R., Allen, E., Fordham, J., Phipps, S., Schneider, H.C., Lindauer, K., Hayes, I., Lockey, J., Pollock, K. and Jupp, R. (2001) Microarray Analysis of Eosinophils Reveals a Number of Candidate Survival and Apoptosis Genes. 
American Journal of Respiratory Cell and Molecular Biology, 25, 425-433. http://dx.doi.org/10.1165/ajrcmb.25.4.4456

[17] Boyum, A. (1968) Separation of Leukocytes from Blood and Bone Marrow. Introduction. Scandinavian Journal of Clinical and Laboratory Investigation, 97, 77-89.

[18] Dussault, A.A. and Pouliot, M. (2006) Rapid and Simple Comparison of Messenger RNA Levels Using Real-Time PCR. Biological Procedures Online, 8, 1-10. http://dx.doi.org/10.1251/bpo114

[19] Manetsch, M., Che, W., Seidel, P., Chen, Y. and Ammit, A.J. (2012) Mkp-1: A Negative Feedback Effector That Represses Mapk-Mediated Pro-Inflammatory Signaling Pathways and Cytokine Secretion in Human Airway Smooth Muscle Cells. Cellular Signalling, 24, 907-913. http://dx.doi.org/10.1016/j.cellsig.2011.12.013

[20] Hu, J.H., Chen, T., Zhuang, Z.H., Kong, L., Yu, M.C., Liu, Y., Zang, J.W. and Ge, B.X. (2007) Feedback Control of Mkp-1 Expression by P38. Cellular Signalling, 19, 393-400. http://dx.doi.org/10.1016/j.cellsig.2006.07.010

[21] Hay, D.W., Torphy, T.J. and Undem, B.J. (1995) Cysteinyl Leukotrienes in Asthma: Old Mediators up to New Tricks. Trends in Pharmacological Sciences, 16, 304-309. http://dx.doi.org/10.1016/S0165-6147(00)89059-8

[22] Chi, H., Barry, S.P., Roth, R.J., Wu, J.J., Jones, E.A., Bennett, A.M. and Flavell, R.A. (2006) Dynamic Regulation of Pro- and Anti-Inflammatory Cytokines by MAPK Phosphatase 1 (MKP-1) in Innate Immune Responses. Proceedings of the National Academy of Sciences of the United States of America, 103, 2274-2279. http://dx.doi.org/10.1073/pnas.0510965103

[23] Kwak, S.P. and Dixon, J.E. (1995) Multiple Dual Specificity Protein Tyrosine Phosphatases Are Expressed and Regulated Differentially in Liver Cell Lines. The Journal of Biological Chemistry, 270, 1156-1160. http://dx.doi.org/10.1074/jbc.270.3.1156

[24] Hendriks, W.J. and Pulido, R. (2013) Protein Tyrosine Phosphatase Variants in Human Hereditary Disorders and Disease Susceptibilities. Biochimica et Biophysica Acta (BBA)—Molecular Basis of Disease, 1832, 1673-1696. http://dx.doi.org/10.1016/j.bbadis.2013.05.022

[25] Shah, S., King, E.M., Chandrasekhar, A. and Newton, R. (2014) Roles for the Mitogen-Activated Protein Kinase (MAPK) Phosphatase, DUSP1, in Feedback Control of Inflammatory Gene Expression and Repression by Dexamethasone. The Journal of Biological Chemistry, 289, 13667-13679. http://dx.doi.org/10.1074/jbc.m113.540799

[26] Quante, T., Ng, Y.C., Ramsay, E.E., Henness, S., Allen, J.C., Parmentier, J., Ge, Q. and Ammit, A.J. (2008) Corticosteroids Reduce Il-6 in Asm Cells via Up-Regulation of MKP-1. American Journal of Respiratory Cell and Molecular Biology, 39, 208-217. http://dx.doi.org/10.1165/rcmb.2007-0014OC

[27] Jin, Y., Hu, D., Peterson, E.L., Eng, C., Levin, A.M., Wells, K., Beckman, K., Kumar, R., Seibold, M.A., Karungi, G., Zoratti, A., Gaggin, J., Campbell, J., Galanter, J., Chapela, R., Rodriguez-Santana, J.R., Watson, H.G., Meade, K., Lenoir, M., Rodriguez-Cintron, W., Avila, P.C., Lanfear, D.E., Burchard, E.G. and Williams, L.K. (2010) Dual-Specificity Phosphatase 1 as a Pharmacogenetic Modifier of Inhaled Steroid Response among Asthmatic Patients. Journal of Allergy and Clinical Immunology, 126, 618-625. e2. http://dx.doi.org/10.1016/j.jaci.2010.06.007

[28] Jeffrey, K.L., Brummer, T., Rolph, M.S., Liu, S.M., Callejas, N.A., Grumont, R.J., Gillieron, C., Mackay, F., Grey, S., Camps, M., Rommel, C., Gerondakis, S.D. and Mackay, C.R. (2006) Positive Regulation of Immune Cell Function and Inflammatory Responses by Phosphatase PAC-1. Nature Immunology, 7, 274-283. http://dx.doi.org/10.1038/ni1310

[29] Li, C., Scott, D.A., Hatch, E., Tian, X. and Mansour, S.L. (2007) Dusp6 (Mkp3) Is a Negative Feedback Regulator of FGF-Stimulated ERK Signaling During Mouse Development. Development, 134, 167-176. http://dx.doi.org/10.1242/dev.02701 